\title{
WEAR RESISTANCE OF 304 AUSTENITIC STAINLESS-STEEL FRICTION WELDED JOINTS
}

\author{
JWAN KHALIL MOHAMMED*, RAMADHAN H GARDI** and DLAIR O. RAMADAN* \\ *Department of Technical Mechanical and Energy Engineering, Erbil Technical Engineering College, Erbil \\ Polytechnic University, Erbil, Iraq \\ ** Dept. of Mechanical and Mechatronics Engineering,University of Salahuddin, Kurdistan Region-Iraq \\ * Department of Technical Mechanical and Energy Engineering, Erbil Technical Engineering College, \\ Erbil Polytechnic University, Erbil, Iraq
}

(Received: January 29, 2020; Accepted for Publication: May 17, 2020)

\begin{abstract}
In the present work, similar joint of AISI 304 austenitic stainless steel with a designed joint interface by $6 \mathrm{~mm}$ diameter and $6 \mathrm{~mm}$ depth, were processed by rotary friction welding route. Different parameters including forging pressure (192.4, 240.5, 288.6 and 384.8 MPa), friction pressure (192.4 MPa), frictional speed $(560 R P M)$ and frictional time (1 min) are examined. Pin on disc wear tester was used for wear test with counter disc SAF 2205 duplex stainless steel and cylindrical AISI 304 pin specimens. The surface roughness of duplex stainless-steel disc was measured. The wear rate in terms of weight loss were obtained for the pin specimens. The results of designed joint interface specimens showed better wear resistance than as-received. The variation of increasing wear loss with sliding distance has been found to be uniform for all the specimens. Further, it was noted from the experiments that the wear rate increased with increasing forging pressure.
\end{abstract}

KEYWORDS: Friction welding, Austenitic stainless steel 304, Microstructure, surface roughness, wear rate.

\section{INTRODUCTION}

Stainless steels are widely used in various areas in practical applications such as hydraulic machinery and in liquid-handling systems (Chiu et al., 2005). In addition, as structural materials widely used in the nuclear, chemical and food industries (Subbiah and Rajavel, 2010) due to excellent corrosion resistance and good weldability (Hajian et al., 2015). Among different types of stainless steels, the AISI 304 is the most common type used. It is a 18/8 standard austenitic stainless steel which has a high ductility, excellent drawing, forming properties. This steel consumed in distinctive applications like chemical, cooking equipment, cryogenic and pressure vessels, hospital surgical equipment, and marine equipment (Ates and Kaya, 2014). Also, it has an excellent stress corrosion cracking resistance and good resistance to pitting and crevice corrosion in chlorine environments. Austenitic-stainless steel is preferred more than other stainless-steel types due to its weld ability properties (Çaligülü et al., 2012). In order to use the materials in wide industries, welding is a compulsory technique. Also the factors such as internal strain, slag, pores, and sensitization phenomenon (Almanza-Casas et al., 2011) and tender intermetallic phases (Mercan et al., 2015) the austenitic stainless steel is preferred to joined by friction welding types.

Rotary fiction welding is a one of solid-state techniques which is used for joining similar and dissimilar materials (Ganesan and Marimuthu, 2016). In this process, the two parts of specimens are contacted. The joint is produces by rotating one of them with the applied pressure, while the other remains stationary (Akbarimousavi and Goharikia, 2011; Zhang et al., 2017). The plastic deformation is occurred near the interface with the help of axial force. If sufficient frictional heat has been produced during softening, the upsetting pressure is increased (Kurt et al., 2011; Li et al., 2012; Uday et al., 2012).

Accordingly, Chowdhury et al., (2013) investigated the friction coefficient and wear resistance for $304 L$ stainless steel disc against 
different pin materials including aluminum, gun metal, copper and brass. The researchers examined different normal load $(10,15$ and $20 \mathrm{~N})$ and sliding velocities $(1,1.5$ and $2 \mathrm{~m} / \mathrm{s})$. In their obtained results found that the friction coefficient decreases with increasing normal load, whereas increased with increasing the sliding velocity. In addition, wear rate increased with increasing normal load and sliding velocity (Chowdhury et al., 2013).

Moreover, Mahmoud (2015) argues that this type of steel cannot be utilized because of its low surface hardness and wear resistance in some environmental conditions. Because of degradation of components during the contact between the components and a flowing or vibrating liquid, cavitation erosion. For this reason, Mahmoud in 2015 assessed the study for increasing the wear resistance of $304 \mathrm{~L}$ stainless steel. The laser cladded with TiC powder have been conducted. TiC powder was added to the cleaned surface to form a layer. Different travelling speeds $(4,8$ and $12 \mathrm{~mm} / \mathrm{s})$ and $2800 \mathrm{~W}$ processing power was used. The researcher reveled that the specimens at $12 \mathrm{~mm} / \mathrm{s}$ traveling speed showed a better corrosion resistance than the stainless-steel substrate. Furthermore, wear resistance improved remarkably for all conditions especially at $12 \mathrm{~mm} / \mathrm{s}$ travelling speed. Additionally, Majumdar et al., (2007), investigated a titanium boride laser surface composite on a $304 \mathrm{~L}$ stainless steel surface substrate. Thus, the authors realized that the wear resistance of laser treated specimens were improved as compare to untreated specimens.
Moreover, they found that the wear mechanism was adhesive and abrasive in as-received stainless steel.

However, A number of studies have been done in order to improve the wear resistance. Most researches on wear has been fabricated the surface composite by adding the reinforcement particles $\left(\mathrm{SiC}, \mathrm{B}_{4} \mathrm{C}\right.$ and $\left.\mathrm{Al}_{2} \mathrm{O}_{3}\right)$ into the weld joint. Unfortunately, the entire attempts have been examined by using friction stir welding. Despites, there is no study of wear resistance improvements for designed joint interface of friction welded AISI 304 austenitic stainless steel. Therefore, the aim of this study is to present the experimental investigation in order to evaluate the wear resistance of austenitic stainless steel 304 with changing joint using rotary friction welding.

\section{Experimental work}

In the present study, the solid rod base metal AISI 304 austenitic stainless-steel with $15 \mathrm{~mm}$ diameter was machined by lathe machine into four samples. The AISI 304 consists of $0.38 \% \mathrm{Si}$, $0.024 \% \mathrm{~S}, 0.036 \% \mathrm{P}, 1.67 \% \mathrm{Mn}, 0.054 \% \mathrm{C}$, $18.2 \% \mathrm{Cr}$ and $8.0 \% \mathrm{Ni}$. The steel microstructure, with a magnification of X600, is shown in Fig.1. The joint interface of specimens was designed to pin shape with a diameter of $6 \mathrm{~mm}$ and pin length of $6 \mathrm{~mm}$ at one side with a specimen length of $40 \mathrm{~mm}$. The opposite side was drilled at the center to a depth of $6 \mathrm{~mm}$ and a diameter of $6 \mathrm{~mm}$ with a specimen length of $60 \mathrm{~mm}$ (due to lathe machine requirements) as shown in Fig. 2.

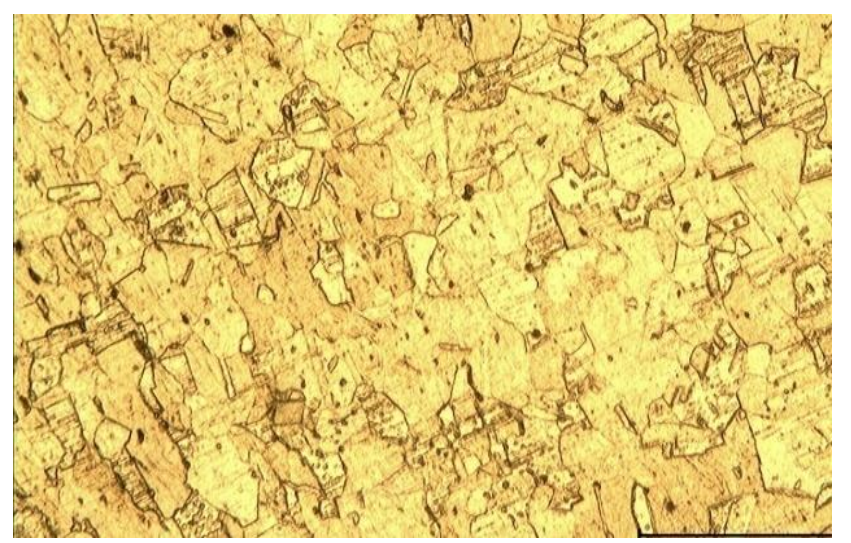

Fig.1: Microstructure of as received AISI 304 austenitic stainless steel (pin) (Magnification X 600) 


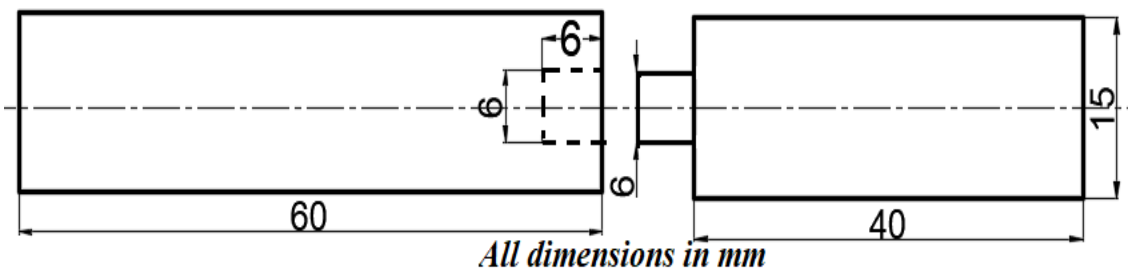

Fig. 2: Schematic diagram of specimens

Then the welding process was performed for the prepared samples using a lathe machine. The experiments were conducted with different parameters such as friction pressure, rotational speed, friction time and forging pressure. The designed joint side (with pin shape) was attached at the rotational side and the drilled side was fixed at the stationary side as shown in
Fig. 3. The four different forging pressures 192.4, 240.5, 288.6 and $384.8 M P a$ were selected, respectively. As well as, constant rotational speed $560 R P M$ and friction pressure 192.4 $M P a$ was used. The entire welding process was performed at one minute.

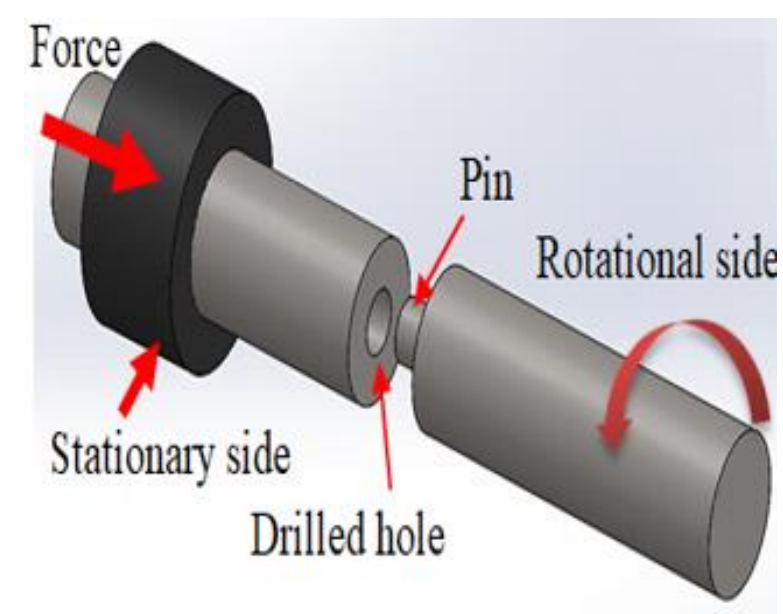

Fig. 3: Schematic of Specimen Set up

\section{Microstructure Test}

The surface of welded AISI 304 stainless steels were prepared to microstructure test, firstly grinded which is the surface of the specimens was flattened with the help of disc and grinding /polishing machine by $\mathrm{Al}_{2} \mathrm{O}_{3}$ emery special sheets with a grit ranges with 320,800 and 1000 grits. This step was continued until the surface was completely free from burrs and scratches in the result of using hacksaw or cut of wheel. Secondly, polishing was performed to further remove scratches from the surface of the specimen. It is polished with a light disc cloth with a help of Bushler /polycrystalline/diamond suspension coolant. The specimens were cleaned by distilled water then dried using a hot air dryer to remove the remained coolant. For further finishing surface re-polishing is done if necessary. Finally, etching was done in order to reveal the grain boundaries and make the 
structural characteristics of this steel visible. The solution is prepared according to ASTM which consists of a saturated solution of $\mathrm{FeCl}_{3}$ in concentrated hydrochloric acid $(\mathrm{HCl})$ to which a little nitric acid $\left(\mathrm{HNO}_{3}\right)$ was added. Each sample was remained inside the etchant solution for 2.50 min. Then, the microstructure analysis was conducted by optical microscope. Subsequently, photographs of the microstructure and the grain size with magnification of $X 600$ were measured and captured using digital camera.

\section{Wear Test}

The welded specimens were prepared according to ASTM: G99-05 standard. The pins of $8 \mathrm{~mm}$ diameter were cut from the weld joint, with the axis of the friction welded joint (pin side) direction and length $25 \mathrm{~mm}$ for all specimens. In addition, the counter face rotating disc was made of a duplex stainless steel (SAF 2205 ) as shown in Fig. 4 which contains a $20.8 \%$ $\mathrm{Cr}, 5.7 \% \mathrm{Ni}, 2.5 \% \mathrm{Mo}, 1.5 \% \mathrm{Mn}, 0.02 \% \mathrm{C}$, $0.94 \% \mathrm{Si}, 0.13 \% \mathrm{~N}, 0.6 \% \mathrm{Cu}$ and $\mathrm{Fe}$ balance.

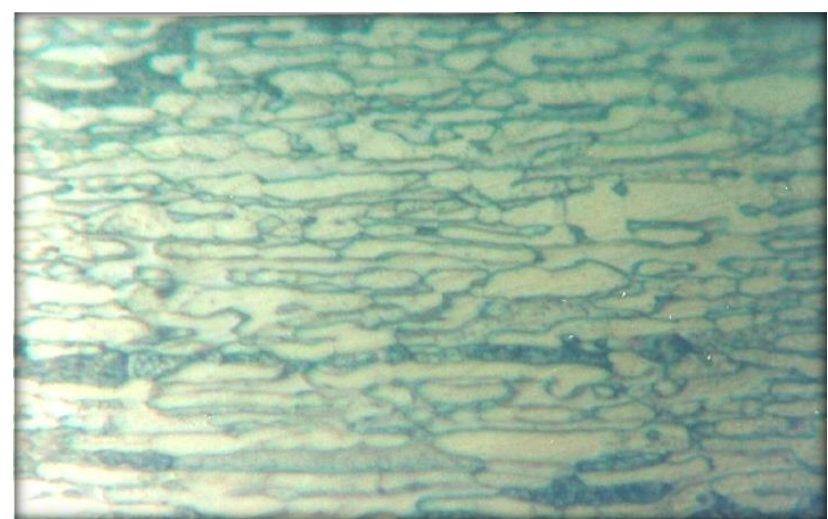

Fig. 4: microstructure of as received duplex stainless steel SAF 2205 (disc) (Magnification X 600)

The schematic configuration of pin-on-disk wear operation shown in Fig. 5.

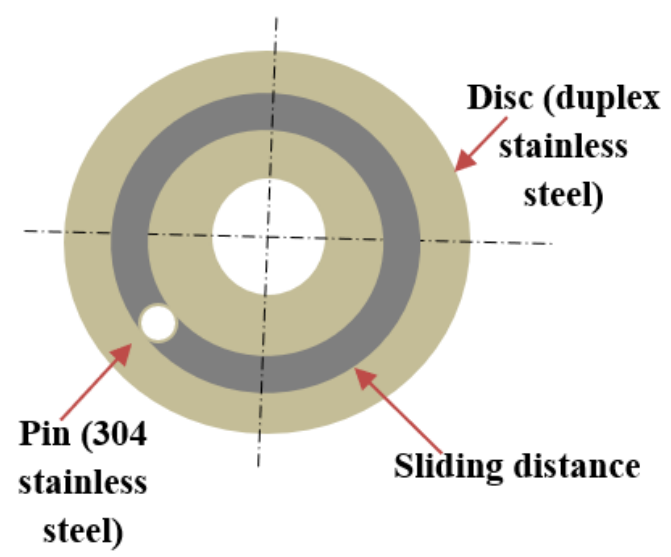

Fig. 5: Schematic Configuration of Pin-on-Disk

Prior to perform wear test the weight of specimens was measured using a digital scale having least count of $0.001 \mathrm{~g}$. During the counter disc was attached to a rotational wheel. On the other hands, the pin was attached in the opposite (stationary) side. Then the wear tests were conducted under dry sliding conditions at room temperature under a constant load $25 \mathrm{~N}$ at the pin side and $12.5 \mathrm{~m} / \mathrm{s}$ linear velocity. Different distances were considered $77.37 \mathrm{~m}, 154.74 \mathrm{~m}$, $232.11 \mathrm{~m}$ and wear rate were determined. The dlair.o.ramadan@epu.edu.iq wear test was conducted after two minutes from contacting the pin with the disc and then repeated every two minutes. Then the weight of the samples were measured before and after conducting the wear test. The difference between both weights is the wear rate. Thereafter, the surface roughness of disc has been measured using Tyler - Hobson surface roughness tester (Talysur-10) (Fig. 6) at different points and the sensor sliding perpendicular on the wear track distance. 


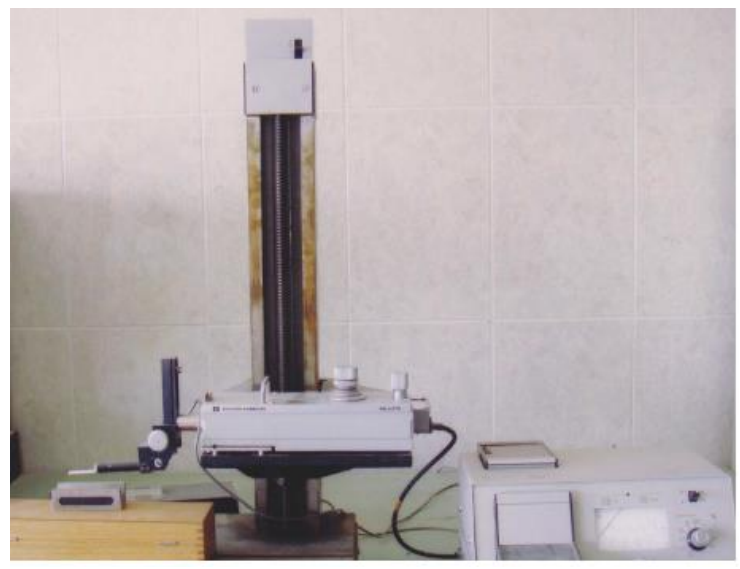

Fig. 6: Surface roughness measurement device

\section{Results and Discussions}

he pin on disk wear test was conducted in order to reveal the wear resistance for four forging pressure cases. The pin was made from 304 austenitic stainless steel and the disk was made from 2205 duplex stainless steel. The results were recorded after performing $77.37 \mathrm{~m}$ , $154.74 \mathrm{~m}, 232.11 \mathrm{~m}$ sliding distances. The wear rate for as-received materials was measured and its variation is shown in Fig. 7. In addition, the variation of wear rate with sliding distance is shown in the sequence of Error! Reference source not found.

Fig. 8 (a-d) respectively. Generally, in both cases (as-received and welded joints) the obtained results showed that the wear rate and siding distance are gradually increased with increasing sliding.

Error! Reference source not found.

Fig. 8 show that the wear rate is gradually increased from $29 \mathrm{mg}$ at sliding distance of $77.37 \mathrm{~m}$ to $33 \mathrm{mg}$ at sliding distance of $154.74 \mathrm{~m}$ then it is dramatically increased to $68 \mathrm{mg}$ at $232.11 \mathrm{~m}$ sliding distance and this attributed to that at final stage, the hard and denies layer of chromium oxide were removed which leads to increasing wear rate. Again, this pattern has been repeated for other three cases (

Fig. $8 \mathrm{~b}$-d). Which is varying from $38 \mathrm{mg}$ to $105 \mathrm{mg}$ then $187 \mathrm{mg}$ at $240.5 \mathrm{MPa}$ forging pressure and from 37 to 95 and $141 \mathrm{mg}$ at 288.6 $\mathrm{MPa}$ forging pressure, finally from 48 to 114 then $210 \mathrm{mg}$ at $384.8 \mathrm{MPa}$ forging pressure.

The above results revealed that the wear rate trends to increase with increasing sliding distance. In accordance with the present results, previous studies had demonstrated that the increase of wear rate with sliding distance was because of duration of rubbing surface. Another possible reason for this is the reduction of shear strength of the material, increased the true area of contact between contacting surfaces (Chowdhury et al., 2013) and increasing coefficient of friction (Rana et al., 2016). On the question of effect forging pressure on wear rate, this study found that the wear rate is increased with increasing forging pressure. For instance, the wear rate at 192.4 $\mathrm{MPa}$ forging pressure and $77.37 \mathrm{~m}$ sliding distance (Error! Reference source not found.

Fig. 8 a) is $29 \mathrm{mg}$ and increased to $38 \mathrm{mg}$, then slightly decreased to 37 and raised up to 48 $m g$ at the 240.5, 288.6 and 384.8 $\mathrm{MPa}$ forging pressure in sequence. This value was much lower than the as-received materials $(181 \mathrm{mg})$ as seen in Fig. 7 at same sliding distance. This reduction of wear resistance under the effect of wear rate is attributed to the increase of carbides in the grain boundaries which is reduced the hardness in these regions. It is suggested that the hardness is correlated with wear rate according to Archard's law. The materials have a higher hardness, achieving lower wear rate due to the increase of the resistance to remove material during sliding (Thangarasu, Murugan and Dinaharan, 2014).

Interestingly, a significant difference was observed between welded and as-received materials. As it is clear that an excellent improvement was revealed at pin interface at 192.4 MPa as compared to other cases and as- 
received material. In general as observed in Fig. 7 and

Fig. 8 the wear resistance of welded joints improved compared to as received materials. This is referred to microstructure changes at the weld joints such as a large amount of carbides and the finer grain size at the joints. In addition to the mentioned reasons above a great number of twins can be seen in which imparts in increasing wear resistance as shown in Error! Reference source not found.. This result is attributed to a higher hardness at the weld zone compared

to others.

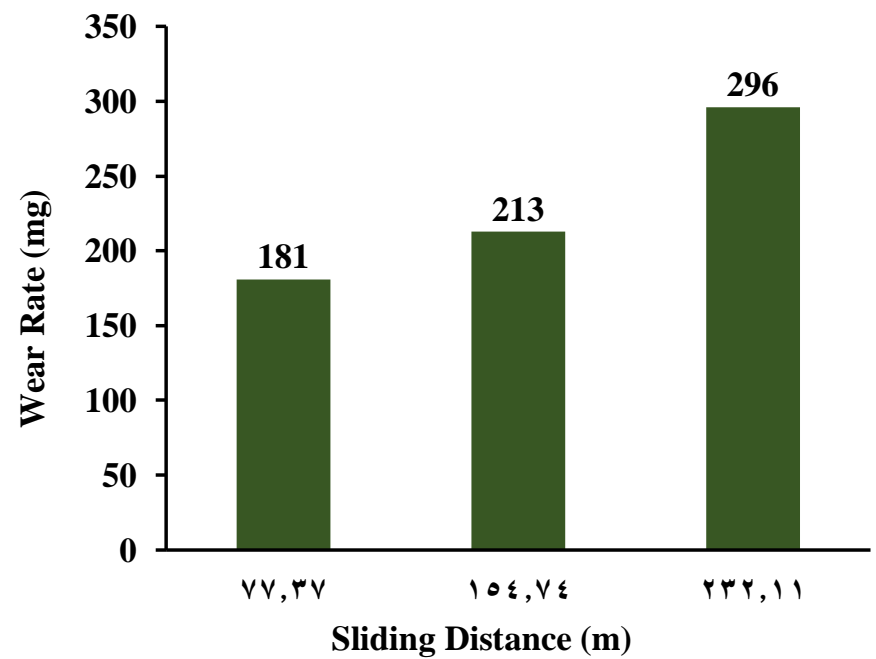

Fig. 7: Variation of wear rate with sliding distance for as-received material
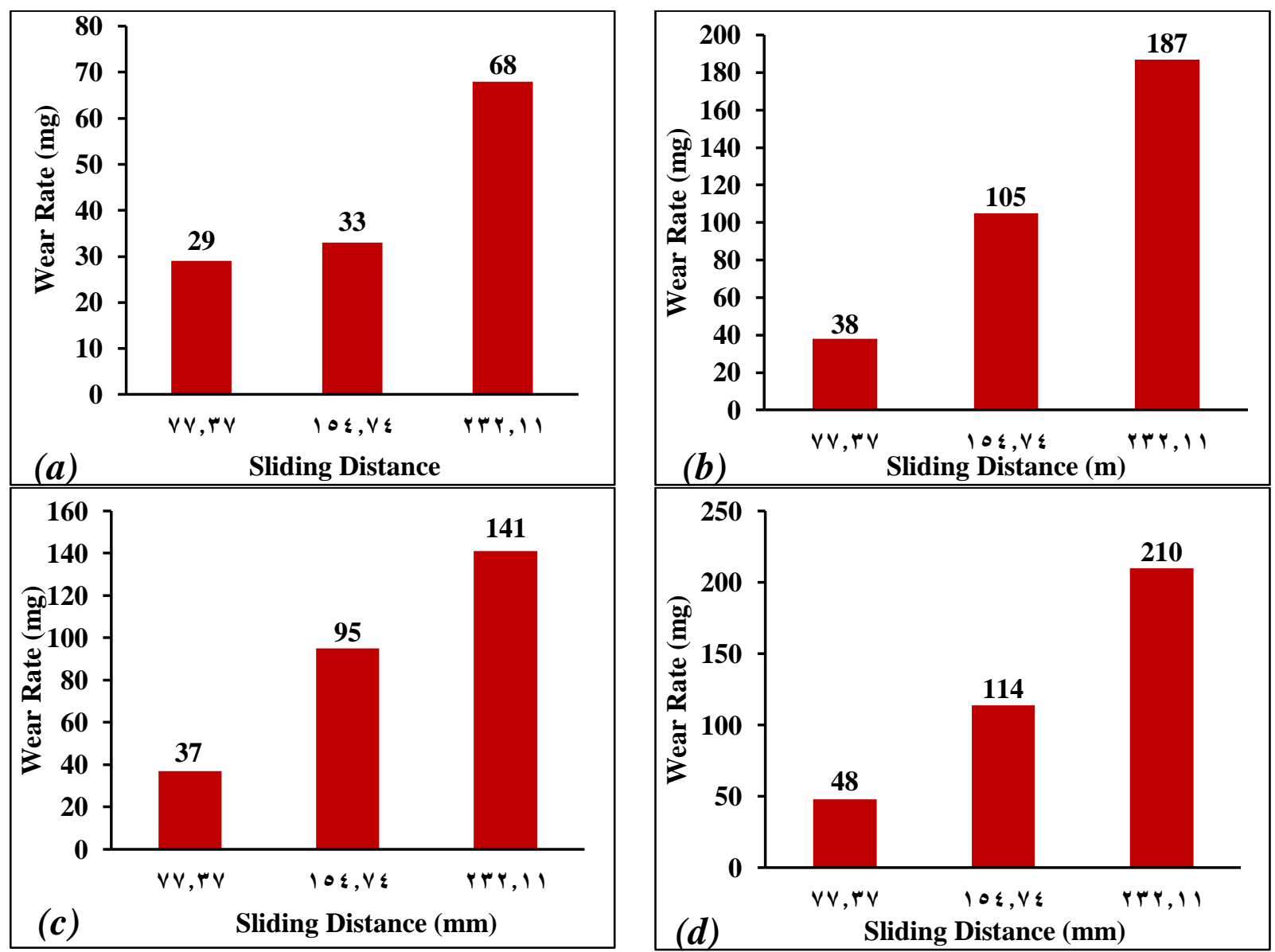

dlair.o.ramadan@epu.edu.iq 
Fig. 8: Variation of wear rate with sliding distance at (a) $192.4 \mathrm{MPa}$, (b) $240.5 \mathrm{MPa}$, (c) 288.6 MPa and (d) $384.8 \mathrm{MPa}$ forging pressure.
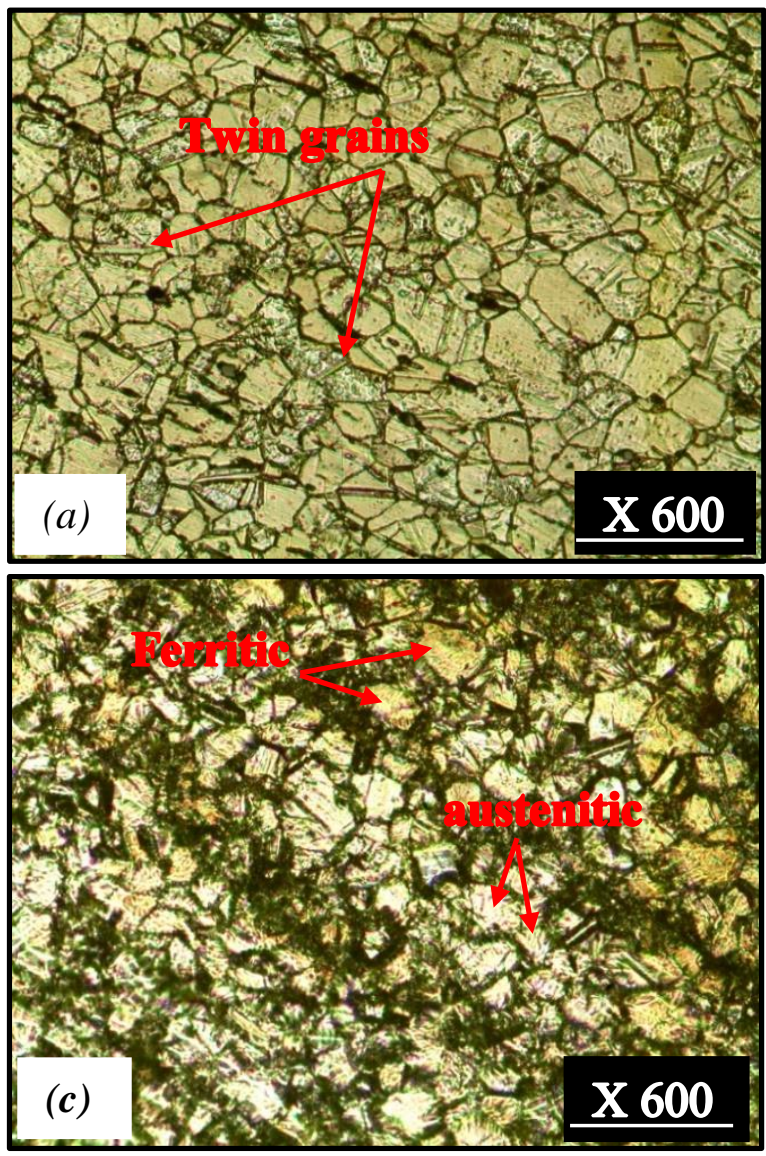
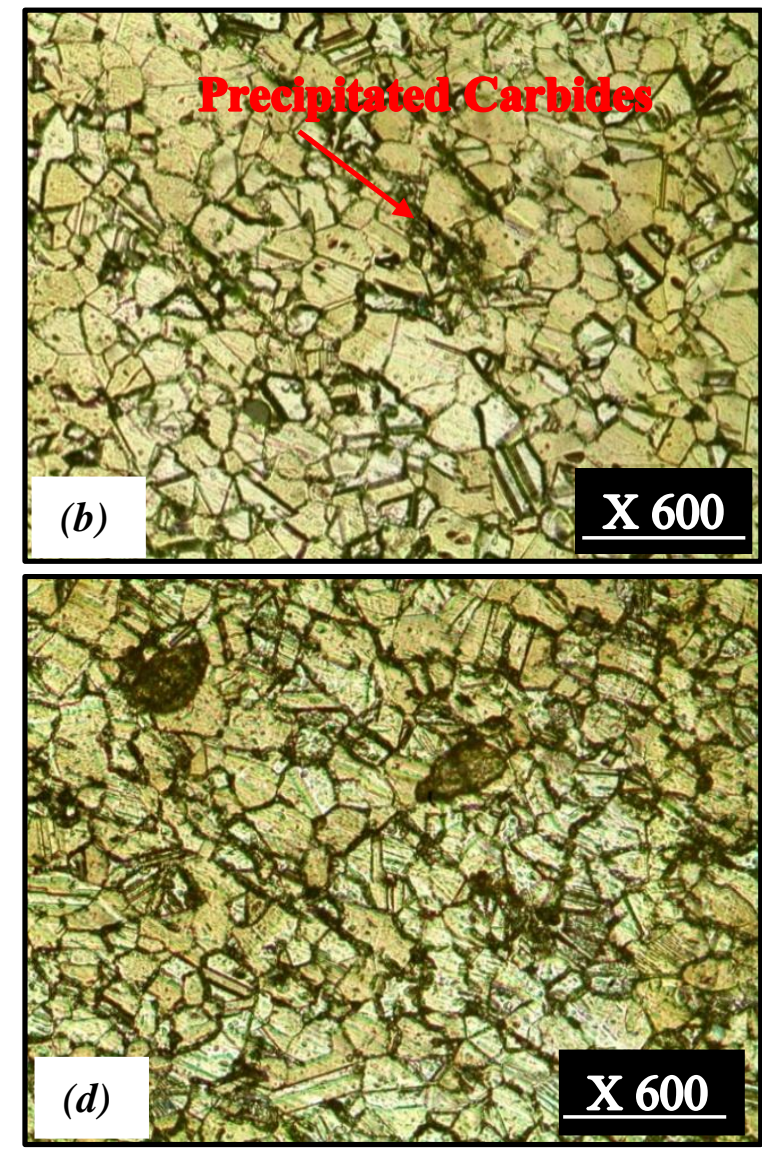

Fig. 9: Microstructure results of AISI 304L austenitic stainless steel at (a) $192.4 \mathrm{MPa}$, (b) 240.5 MPa, (c) 288.6 $\mathrm{MPa}$ and (d) $384.8 \mathrm{MPa}$ forging pressures.

The surface roughness of wear track on the SAF 2205 duplex stainless steel disc during $232.11 \mathrm{~m}$ sliding distance of $304 \mathrm{SS}$ pin in as received condition is $0.9 \mu \mathrm{m}$. The average surface roughness on SAF 2205 duplex stainless steel disc during $232.11 \mathrm{~m}$ sliding distance of friction welded 304 austenitic stainless-steel joints is plotted in Fig. 10. As it is shown in the graph, when the forging pressure of joints increased from 192.4 to $240.5 \mathrm{MPa}$ the surface roughness decreased from 1.3500 to $1.2375 \mu \mathrm{m}$ and reached to its minimum value $0.862 \mu \mathrm{m}$ for the specimens welded with 288.6 $M P a$ forging pressure and beyond that suddenly increased to $1.23 \mu \mathrm{m}$ at $384.8 \mathrm{MPa}$. In the comparison of the surface roughness between the stainless-steel $S A F$ 2205-disc material at $232.11 \mathrm{~m}$ sliding distance and the as-received materials, the surface roughness is significantly increased except the samples at 288.6 $\mathrm{MPa}$. The results attributed to microstructural changes like creation of different carbides that occurs at pin material during welding due to different heat and plastic deformation. The current study has confirmed that surface roughness and forging pressure were negatively associated. 


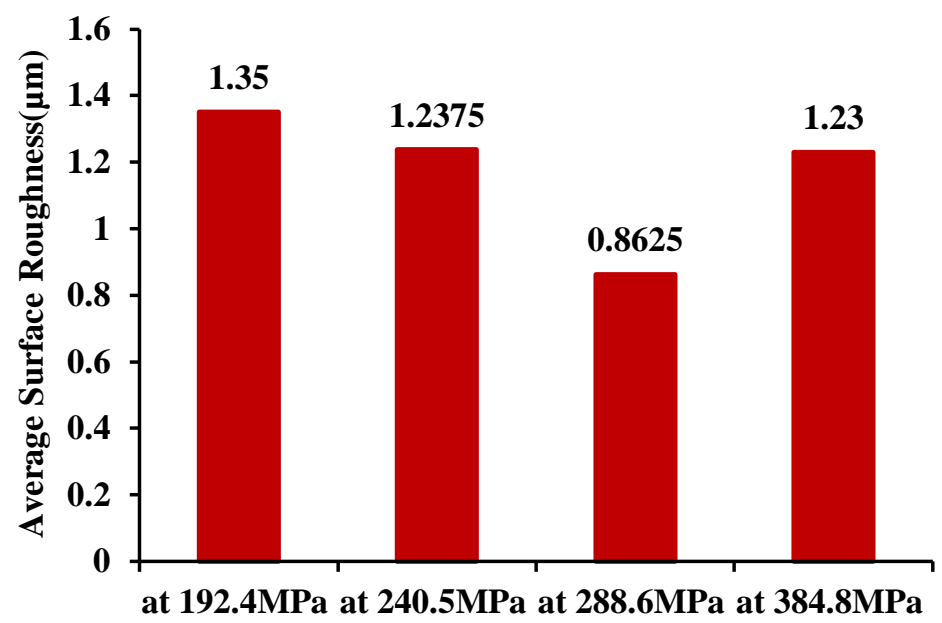

Fig. 10: Average surface roughness of disk at different forging pressure cases

\section{CONCLUSIONS}

Wear resistance tests of friction welded joints of AISI 304 austenitic stainless steel were performed and the following conclusions have been obtained:

1. The friction welding of AISI 304 austenitic stainless steel improves wear resistance.

2. The minimum wear rate was $29 \mathrm{mg}$ at 192.4MPa forging pressure.

3. The maximum wear rate was $210 \mathrm{mg}$ at 384.8MPa forging pressure.

5. The lowest surface roughness on SAF 2205 $D S S$ disc can be obtained when 304 ASS pin friction welded with $288.6 \mathrm{MPa}$ forging pressure.

\section{REFERENCES}

- Akbarimousavi, S.A.A., Goharikia, M., 2011. Investigations on the Mechanical Properties and Microstructure of Dissimilar cp-Titanium and AISI 316L Austenitic Stainless Steel Continuous Friction Welds. Mater. Des. 32, 3066-3075.

- Almanza-Casas, E., Perez-López, M.J., Steel, R., Packer, S., 2011. Evaluation of Mechanical Properties of 304L and 316L Stainless Steels Friction Stir Welded. Int. Offshore Polar Eng. Conf. 8, 530-533.

- Ates, H., Kaya, N., 2014. Mechanical and Microstructural Properties of Friction Welded AISI 304 Stainless Steel to AISI 1060 Steel AISI 1060. Arch. Metall. Mater. 59.

- Çaligülü, U., Dikbaş, H., Taşkin, M., 2012. Microstructural Characteristic of Dissimilar Welded Components (AISI 430 Ferritic-AISI 304 Austenitic Stainless Steels) by CO2 Laser
Beam Welding (LBW). Gazi Univ. J. Sci. 25, 35-52.

- Chowdhury, M.A., Nuruzzaman, D.M., Roy, B.K., Dey, P.K., Mostafa, M.G., Islam, M.S., Mia, M.R., 2013. Experimental Investigation on Friction and Wear of Stainless Steel 304 Sliding Against Different Pin Materials. World Appl. Sci. J. 22, 1702-1710.

- Ganesan, M., Marimuthu, P., 2016. Experimental Investigation of Tensile Strength Behavior on Friction - Welded Austenitic Stainless Steel Grade 304L Joints. Int. J. Appl. Eng. Res. 11, 1251-1255.

- Kurt, A., Uygur, I., Paylasan, U., 2011. Effect of Friction Welding Parameters on Mechanical and Microstructural Properties of Dissimilar AISI 1010-ASTM B22 Joints. Weld. J. 90, 102-106.

- Majumdar, J.D., Ramesh Chandra, B., Manna, I., 2007. Laser composite surfacing of AISI 304 stainless steel with titanium boride for improved wear resistance. Tribol. Int. 40, 146152.

- Mercan, S., Aydin, S., Özdemir, N., 2015. Effect of Welding Parameters on the Fatigue Properties of - Dissimilar AISI 2205-AISI 1020 Joined by Friction Welding. Int. J. Fatigue 81, 78-90.

- Rana, H.G., Badheka, V.J., Kumar, A., 2016. Fabrication of Al7075 / B4C Surface Composite by Novel Friction Stir Processing (FSP) and Investigation on Wear Properties. Procedia Technol. 23, 519-528.

- Thangarasu, A., Murugan, N., Dinaharan, I., 2014. Production and wear characterization of AA6082-TiC surface composites by friction stir processing. Procedia Eng. 97, 590-597. 